\title{
USABILITY EVALUATION AS QUALITY ASSURANCE OF E-GOVERNMENT SERVICES The E-Poupatempo Case
}

Lucia Filgueiras ${ }^{1}$, Plinio Aquino Jr. ${ }^{1}$, Vera Tokairim ${ }^{2}$, Carlos Torres ${ }^{2}$ and Iara Barbarian $^{2}$

${ }^{l}$ Escola Politécnica, University of São Paulo. Av. Prof Luciano Gualberto, t3 -158 São Paulo, SP Brazil; ${ }^{2}$ Prodesp, Poupatempo. Rua Florêncio de Abreu 848, São Paulo, SP Brazil

Abstract: This paper describes the role of usability evaluation as quality assurance of egovernment services. Usability evaluation intends to identify difficulties experienced by a user when interacting with a computer interface. Usability evaluation is a key issue in assessing the return from investment in government sites, as it can measure how the services impact the citizen and is a significant source of requirements for design reviews of present services. This paper describes the creation of a Laboratory for Human-Computer Interaction (LabIHC) devoted to assess Sao Paulo State, Brazil, government services usability. This Laboratory evaluates about 250 users per day using different egovernment services and can produce accurate reports on usability problems. The paper describes LabIHC's pluralistic evaluation methodology, composed of four different techniques, as well as the set of recommendations that were derived from LabIHC results for e-government services.

Key words: e-govemment; usability; universal usability; usability evaluation.

\section{INTRODUCTION}

Several initiatives demonstrate the Brazilian government effort to use Information Technology as an effective means of bringing together citizens and government, by making available information of public interest and enhancing services efficiency.

Usability is a main issue in e-government applications. Any interactive system must be checked for human usage suitability, but in e-government 
applications, usability is more than a design goal: it is a tool for democracy. If a bad design in e-commerce, for example, can drive away a customer definitely, a bad design in e-government can result in a citizen being alienated from important information or from a necessary service.

However, there is no simple way to define usability in e-government applications. Many nations are presently facing the challenge of developing interfaces for user groups that are diverse in their needs and in their knowledge of computer technology ${ }^{1}$. In developing countries, e-government application designers have an additional challenge of designing for citizenship education and social inclusion.

This paper proposes a methodological approach to the usability-in-egovernment problem. It presents the initiative of São Paulo State government in Brazil to install a Usability Laboratory (LabIHC - Laboratory for Human-Computer Interaction) for monitoring usability of present egovernment services so that designers can objectively remove barriers to effective use of those services. Section 2 in this paper presents usability concepts applied to e-government applications.

Usability evaluation helps assure appropriateness of governmental investments. A reliable evaluation process closes the quality cycle through monitoring of how citizens actually use the services.

Being in charge of observing the real use of government services and identifying difficulties citizens may be facing when interacting with these services, LabIHC acts as a prototype for an e-govemment Quality Assurance service, conforming to recent directives of the São Paulo State Committee for Quality in Public Management. Section 3 presents the institutional environment for LabIHC.

A single usability evaluation technique is not effective in identifying usability problems. Section 4 presents LabIHC's pluralistic methodology for usability evaluation, composed of four different techniques.

Usability problems resulting of LabIHC evaluation are reported to service designers. In order to help them avoid common usability problems, a set of guidelines was developed and resulted in the e-poupatempo usability standard (eUS) for evaluating e-government transactional services. A discussion of these guidelines is presented in Section 5.

\section{USABILITY FOR E-GOVERNMENT SERVICES}

Even though Usability Engineering is an over 10-year old discipline, only recently the Internet pressure for better interaction with non-technical users has led to a more significant and systematic concern about human-computer interface. 
Usability is defined as the ability of a human-computer interface to be easily and efficiently used by humans. ISO/IEC $9126^{2}$ defines usability as composed by attributes of learnability, understandability and operability. Subjective and emotional aspects such as helpfulness and satisfaction also play an important role in usability.

Designers must employ user-centered development processes in order to produce a computer application that can be used efficiently and comfortably by different users. Usability evaluation techniques play an important role in this process. A Usability Laboratory is an environment where computer application usage is observed, monitored, experimented and analyzed, in order to identify obstacles faced by users. Different e-government services have different audiences. Sometimes, obstacles are due to human behavior. Many times, though, errors and difficulties arise from design. More than often, obstacles are different for different user profiles.

A recent research published by Accenture ${ }^{3}$ identified that governments are simultaneously tailoring service delivery to meet citizens' needs and demanding that projects to deliver Return on Investment. Usability evaluation can report on changes needed to make a service suitable to a user population. Quantitative data can help a more controlled use of project budget. Also, by establishing the present usability level of an application, monitoring usability level improvement is a valuable proof of the return from government investment.

\section{ENVIRONMENT FOR THE USABILITY EVALUATION: LABIHC AND THE E- POUPATEMPO PROJECT}

São Paulo State in Brazil has a population of about 40 million people, in a 250.000-square-kilometers territory, meaning a need for access comparable to many countries in Europe. E-government challenges for SP are to provide updated and universally accessible government information. This is a key challenge in Brazil, where the rate of computers per inhabitants is still low. Besides increasing the availability of computers, through programs of distribution of equipment in schools and in needy communities, SP State program for e-govemment is strongly oriented towards educating the citizen to be an autonomous, proactive user of e-govemment services.

Poupatempo ("save time", in Portuguese) is a successful project of the Sao Paulo state government that provides a single locale wherein several public services are available to citizens. E-poupatempo is the virtual version of this project and is a portal where public services are gathered for easy ac- 
cess. Presently, public service processes are being integrated and optimized in order to free citizens from displacement and bureaucracy ${ }^{4}$.

Considering that lack of access to computers is a major obstacle to universal usability in Brazil, a special place for e-government services was created in one of the Poupatempo stations as a prototype. In this location, citizens can access any government or public interest internet site, aided (if necessary) by trained personnel that assist the user both in completing the intended use and in manipulating the computer.

LabIHC, Laboratory for Human-Computer Interaction, is part of epoupatempo project. LabIHC was set by a joint effort of the Sao Paulo State Secretaria da Casa Civil, Prodesp (the State IT company) and Poupatempo Superintendence, technically assisted by the Software Technology Laboratory at Escola Politécnica, University of São Paulo.

LabIHC is responsible for identifying barriers posed to citizens in the service usage. The innovation of LabIHC compared to other usability labs is its ability to observe hundreds of real users per day. LabIHC benefits from the fact that about 250 citizens per day go spontaneously to the epoupatempo station. To date, this database amounts to more than 60.000 usage records, which lead to quantitative results with statistical significance. Also, specific experiments are developed for testing more rare usage conditions and prototypes, thus contributing towards improving quality in $\mathrm{G} 2 \mathrm{C}$ relationship.

\section{LABIHC PLURALISTIC APPROACH TO US- ABILITY EVALUATION}

Combined evaluation techniques are known to be more effective than one single method ${ }^{5}$. LabIHC employs a set of techniques to deliver more comprehensive results to e-government service designers.

Some of the difficulties captured in LabIHC evaluations are quite obvious to an expert eye; others are rare exceptions that only real usage could have raised. Due to the diverse nature of these difficulties, one single approach to Usability Laboratory would not capture a significant amount of usability problems.

LabIHC, thus, evaluates usability through a pluralistic approach, in which user profile and usage experience are collected by four different techniques:

- Direct observation. Attendants observe usage and keep a record of every user experience with computers and user profile.

- Questionnaires answered by a sample of the population, in order to map subjective expectation and satisfaction. 
- Formal experiments, which address rare cases or alternative designs.

- Usability expert inspections based on usability criteria.

LabIHC delivers usability evaluation results as Usability Evaluation Reports (UERs) that are sent to the service providers upon request. UERs contain data about user profile and a detailed description of difficulties experienced by the users. UERs are intended to be used for design reviews.

\subsection{Role of attendants}

A key success factor for LabIHC methodology is the role played by epoupatempo attendants. Their main duty is to help citizens with whatever need they have while performing the e-government services. Because of their close contact with citizens' needs and difficulties, they were assigned the task of collecting usability information. As public workers, their observation does not violate citizens' privacy. No information about the user identity is collected.

Attendants work as agents for universal usability, as they "bridge the gap between what users know and what they need to know"6. Answering citizens' questions, they gather a valuable knowledge of each site weaknesses. They encourage citizens to use the computer service by themselves in order to raise doubts and difficulties ${ }^{7}$. Even though the citizen has never used a computer before, he or she is invited to try and is frequently successful.

The traditional usability approach of having usability experts to monitor usage had to be discarded because the citizen cannot be constrained or embarrassed while using a public service that may require personal and confidential data. Video recording was also discarded because it would depend on each citizen's personal authorization, and this would not be feasible in a 250-user-per-day basis, besides generating a prohibitive amount of data that would be very difficult to analyze.

Success of attendants as usability observers depends heavily on training in usability concepts and methodology. As users ask for help, if there is a usability problem, the question is classified and registered. While this procedure makes the process independent of attendants' observation accuracy, the process is still dependent on his or her ability to classify questions as usability problems.

\subsection{Usability variables}

LabIHC evaluation methodology addresses a set of variables that describe the user and his/her usage experience. Independent variables describe citizen profile and can be conditioners of use: age, socio-economical situation, declared experience with computers and frequency of Internet access. 
Dependent variables characterize usage profile and express usability parameters:

- User performance, measured by the service duration

- User proactivity, as the reaction of the user to the autonomous use of the computer, judged as a proactive or passive behavior

- Usage difficulties and their nature

- User expectancy and satisfaction

\subsection{Direct observation}

Direct observation protocol is computed for $100 \%$ of services performed and transferred to databases. This instrument collects variables that can be obtained by attendants, by observation or simple questions. Objective information collected this way contributes to evaluate the efficiency usability goal. Some important information that can be easily extracted from direct observation database is:

- Service time

- User profile for declared experience with computers and the Internet

- Difficulties profile for the service

- Users' proactivity profile

- Required assistance index

This technique has the advantage of resulting in statistically significant, quantitative data.

\subsection{Expectation and Subjective Satisfaction Assessment}

Questionnaires are distributed to a sample of the population, intending to collect information on data that cannot be observed directly by attendants such as age and income and also information of subjective nature, like perceived security, duration of service, ease of use and suitability of human assistance.

User satisfaction is traditionally evaluated in usability studies. However, first applications of questionnaires had to be discarded, because they resulted in a positive biased return. This was explained by the citizens' extremely negative expectation of public services quality. LabIHC team now collects subjective data of expectation for the subjective variables thus representing more reliably citizens' emotions towards the service.

Satisfaction evaluation can return information on whether the user will be inclined to perform the service by him/herself, in a future occasion. This technique has the advantage of resulting in subjective data, yet in a statistically significant, quantitative way. 


\subsection{Usability experiments}

Usability experiments are used either to rehearse special conditions that do not frequently occur or to evaluate prototypes. Usage scenario image and sound are recorded for late review. Subjects for the test are recruited by invitation. LabIHC is especially conscious of ethical aspects of testing and recording humans.

One of the advantages of this technique is the ability to document difficulties and communicate them to designers.

\subsection{Expert evaluation}

In an expert evaluation technique, the usability expert can determine if a certain aspects of a specific product or web site follows recognized usability principles and guidelines.

There are many different kinds of expert evaluation techniques. The process is best done by someone who is knowledgeable in usability issues and/or has some familiarity with the product domain. LabIHC evaluates a service by both usability experts and also by attendants. Together, they can list a large number of usability problems.

This technique has the advantage of being fast and in finding an important quantity of usability problems. Yet, it is a qualitative technique.

\section{THE E-POUPATEMPO USABILITY STANDARD}

LabIHC evaluation experience has led to a set of recommendations intended to avoid most frequent difficulties faced by citizens.

These recommendations represent the e-poupatempo Usability Standard (eUS) for transactional e-government services. Those issues sometimes go beyond ISO/IEC 9126 definition of Usability and should be interpreted broadly as a framework for Quality Assurance in citizen-computer interaction. By following these recommendations, a transactional service is expected to meet the e-poupatempo usability goals, defined as:

- Citizens must be able to complete the service (success)

- Citizens must want to do it again by themselves (proactivity)

eUS recommendations are intended to be used complimentarily to the many more general guidelines of human-computer interaction and web design available in literature (for example, see work by Nielsen ${ }^{8}$, the FAA Human Factors Design Standard ${ }^{9}$ and Microsoft web guidelines ${ }^{10}$ ) and in egovemment publications ${ }^{11}$. Specifically, eUS is complimentary to the Brazilian Federal Government recommendation for Internet sites ${ }^{12}$. 
Table 1 summarizes eUS issues, grouped by usability aspects.

\subsection{Content}

Content recommendations ensure that information is suitably oriented to citizen needs. Relevance is how much information is meaningful to the user.

Table 1. Usability aspects for eUS (e-poupatempo Usability Standard)

\begin{tabular}{|c|c|c|}
\hline Aspect & Definition & Issues \\
\hline Content & $\begin{array}{l}\text { Information quality, independent } \\
\text { of media }\end{array}$ & $\begin{array}{l}\text { Relevance } \\
\text { Coverage } \\
\text { Sequence of service } \\
\text { Content management }\end{array}$ \\
\hline Presentation & How the content is exhibited & $\begin{array}{l}\text { Aesthetics } \\
\text { Structure } \\
\text { Navigability } \\
\text { Error management } \\
\text { Accessibility }\end{array}$ \\
\hline Credibility & $\begin{array}{l}\text { Ability to support and preserve } \\
\text { citizens' confidence in the ser- } \\
\text { vice }\end{array}$ & $\begin{array}{l}\text { Timeliness } \\
\text { Updating } \\
\text { Reliability } \\
\text { Security } \\
\text { Monitoring }\end{array}$ \\
\hline Relationship & $\begin{array}{l}\text { Communication between citizens } \\
\text { and services }\end{array}$ & $\begin{array}{l}\text { Language suitability } \\
\text { Community involvement } \\
\text { Customization } \\
\text { Promotion }\end{array}$ \\
\hline
\end{tabular}

A citizen accessing an e-government service is frequently solving a problem or looking for necessary information on rights and duties, motivated by a compulsory need instead of looking for entertainment or pure knowledge. Also, content must have coverage of alternative means of performing the same service, depending on user needs. Also, citizens should find information on situations that cannot be handled electronically.

Lack of understanding of service sequence has been one of the major reasons for difficulties. Services should present a clear sequence for their performance. Interruptions in the service flow due to the lack of a document or information cause serious trouble to citizens, so citizens should be clearly informed on all prerequisites for service. In the service end, a clear result 
must be presented to the user, as well as recommendations of how to proceed in his problem-solving - for instance, mailing a document to some government office.

Content management guidelines address the need for establishing responsibility for the content as well as references to other government branches or third-party information providers.

\subsection{Presentation}

Presentation guidelines refer to look and feel aspects of the site service. Aesthetics guidelines address the equilibrium of multimedia usage to convey a feeling of modernity and professionalism and stimulate predisposition to interaction success. Structure guidelines intend to ensure an error-free, predictable navigation. Navigability guidelines address reachability through URL and visibility by other public portals and search engines.

Error management guidelines intend to reduce the observed feeling of uncertainty experienced by occasional e-government users, keeping the citizen informed about results. Accessibility guidelines ensure that content is not image or sound dependant and that handicapped users can access service appropriately.

\subsection{Credibility}

The concept of credibility is associated to mechanisms that stimulate and keep the confidence assigned by a citizen to the website. In e-government services, trustworthiness in an e-government site is generally extended to the Government and to the branch responsible for the service. The same will happen if the site is not dependable.

Timeliness is frequently associated to response time and thus affected by communication bandwidth. In e-government services, response time requirements are less restrictive than in e-business applications, for the alternative is the personal service usually far more complicated and time consuming. In spite of that, timeliness guidelines must be associated to usefulness of results, mainly for those services that require manual intervention by some government officer. Site credibility is much impaired by obsolescence. Outdated information can lead the citizen to monetary and time loss and - even more difficult to recover from - to a state of error in concepts or procedures. eUS guidelines for updating issues care for information on change dates and frequency of updates.

Reliability guidelines state the need for correct and valid information, while security guidelines state recommendations for interface tools for informing citizens on policies for protecting their privacy, mainly in public 
computers. Monitoring guidelines assert requirements for informing the citizen on user and service performance data.

\subsection{Relationship}

Relationship aspect covers the usability of the communication channel between citizen and government, through the e-government service.

Language suitability is one of the most difficult issues of relationship for e-government services, even though Brazil, unlike many other countries, benefits from a single language speaking population. However, there is a significant disparity in education and literacy levels. Popular names given to documents and services represent today a barrier for many people in finding correspondence between their problem and the e-government service solution. Also, present e-government services are polluted by "legalese" and bureaucratic language often incomprehensible to users. eUS guidelines require a terminology balance to be achieved, so that the citizen can be guided into in recognizing the correct wording but can be directed to it by his or her known alias term. Language suitability also addresses the minimalist use of interaction widgets that are recognized as barriers for some populations.

Citizens' questions and suggestions result in continuous improvement of services. Communication guidelines help designers define usable communication channels for diverse user profiles. For instance, only a small parcel of the population have email address, so guidelines require alternative means of communication, such as telephone or regular mail

From the citizen's point of view, service quality is also measured by its ability to recognize him or her as an individual, as well as recalling her or his usage history and adapt to it. Customization is issued by eUS guidelines in an evolutionary set of requirements that will help designers to implement CRM features in a near future.

Finally, promotion of e-government services is another important usability issue. Many services are not used only because citizens have never heard about their rights. Promotion guidelines help not only an easier access to the services but more than that, aim to be a factor for citizenship education.

\section{CONCLUSION}

Usability is a complex issue, yet essential for e-government services. Huge amounts of money will be spent in the next years in order to change citizen-to-government to a modern, improved new paradigm of electronic services. 
Different government services have different target audiences, each with their peculiar difficulties. One government service may have children who use computers at school as a target population; rural population that seldom has access to computers may access another one. Therefore, there is no simple answer to usability issues in e-government. This paper addressed the establishment of a governmental usability monitoring and quality assurance service as an answer to the need of knowledge about people and their true difficulties. e-poupatempo LabIHC can act effectively because of closeness to true usage in a unique environment.

Usability evaluation can act as a compass to aid managers in the alwaysdifficult task of allocating project budget. More than that, usability evaluation is the only way to prove that this effort is reaching the citizen.

\section{REFERENCES}

1. ACM Interactions Special Issue 2003 HCI in Developing World, March-April 2003.

2. International Organization for Standardization, International Electrotechnical Commission, International Standard ISO/IEC9126 Information Technology - Software product evaluation - Quality characteristics and guidelines for their use. Geneva, 1991.

3. Accenture, eGovernment - More customer focused than ever before (April 29, 2004) digitalforum.accenture.com/DigitalForum/Global/CurrentEdition/Features/egov_more_cust_focuse d.htm

4. Governo do Estado de São Paulo, Projeto e-poupatempo, 2002 (in Portuguese)

5. F.B.Wood et alii, A practical approach to e-government web evaluation, IEEE IT Pro, May-June, 2003.

6. B. Shneiderman, Universal usability, A CM Comm. 43, 5.

7. L.V.L Filgueiras, C.Torres and I. Barbarian, Next time I'll do it all by myself: enforcing proactivity of novice e-government users (April 29, 2004); www.acm.org/sigs/sigchi/cuu2003/Next time Ill do it all by myself.pdf

8. J. Nielsen, Designing Web Usability, New Riders, 2000

9. V. Ahlstrom, K. Longo, Human Factors Design Standard, Report Number DOT/FAA/CT03/05-HF-STD-001,2003

10.K. Keeker, Improving web site usability and appeal (April 29, 2004); http://msdn.microsoft.com/library/en-us/dnsiteplan/html/improvingsiteusa.asp

11. Online Office of the e-Envoy, Web guidelines (April 29, 2004); http://www.e-envoy.gov.uk/Resources/WebGuidelines/fs/en

12. Brasil, Comitê Executivo do Governo Eletrônico, Resolução no. 7 de 29 de julho de 2002 (in Portuguese), (April 29, 2004);

http://federativo.bndes.gov.br/destaques/egov/docs/resolucao7_egov.pdf 